\title{
Synthesis and Self-assembly of [60]Fullerene Containing Sulfobetaine Polymer in Aqueous Solution
}

\author{
P. RAVI ${ }^{1}$, S. DAI ${ }^{1}$ and K.C. TAM $^{1, *}$ \\ ${ }^{1}$ Singapore-MIT Alliance, \\ School of Mechanical and Aerospace Engineering, Nanyang Technological University, 50 Nanyang Avenue, \\ Singapore 639798 Republic of Singapore
}

\begin{abstract}
A well-defined PDMAEMA- $\boldsymbol{b}-\mathrm{C}_{60}$ was synthesized using ATRP technique and betainized with 1, 3-sulfobetaine to yield Bet-PDMAEMA- $b-C_{60}$. The solution properties were then studied by light transmittance, laser light scattering and transmission electron macroscopic techniques. It was found that Bet-PDMAEMA- $b-C_{60}$ exhibits an upper critical solution temperature (USCT) similar to that observed for BetPDMAEMA in aqueous solution. However, modification of Bet-PDMAEMA with a $\mathrm{C}_{60}$ molecule increases the UCST of the polymer solution, which is a function of the solution ionic strength. Small amounts of salt increase the UCST due to the polyelectrolyte effect, while excess amount of salt leads to a decrease in the UCST attributed to the anti-polyelectrolyte effect. In aqueous salt solution, Bet-PDMAEMA- $b-C_{60}$ chains self-assemble into aggregates that coexist with unimeric BetPDMAEMA- $b-C_{60}$ chains. TEM studies revealed that the system agglomerates when the temperature exceeds the UCST.
\end{abstract}

Key words - ATRP, Fullerene, stimuli-responsive, UCST

\section{INTRODUCTION}

[60]Fullerene $\left(\mathrm{C}_{60}\right)$ exhibits unique properties such as electronic ${ }^{1}$, conducting ${ }^{2}$, magnetic, and high cohesive forces between $\mathrm{C}_{60}$ molecules ${ }^{3}$, ability to accept and release electrons ${ }^{4}$, and relatively high reactivity that allows tailoring of $\mathrm{C}_{60}$ based derivatives, ${ }^{5,6}$, which holds promising end-use applications ${ }^{7,8}$. However, the complete lack of solubility in most organic solvents and aqueous solution hampers its processability and potential applications. Several methods have been adopted to increase its solubility, for example, by forming complexes

This work was supported by the Singapore-MIT Alliance, Singapore.

P.Ravi is with Singapore-MIT alliance, Molecular Engineering for Biological and Chemical Science, School of Mechanical and Aerospace Engineering, Nanyang Technological University, Singapore 63978

S. Dai was with Molecular Engineering for Biological and Chemical Science, Singapore-MIT alliance, School of Mechanical and Aerospace Engineering, Nanyang Technological University, Singapore 63978

K. C. Tam is is with Molecular Engineering for Biological and Chemical Science, Singapore-MIT alliance, School of Mechanical and Aerospace Engineering, Nanyang Technological University, Singapore 63978. phone: +65-6790-5590; e-mail: mkctam@ ntu.edu.sg. with surfactants or cyclodextrins through solubilization and encapsulation, ${ }^{9,10}$ producing charge-transfer (CT) complex with organic compounds bearing electron donating groups through electron donor and acceptor interaction, and conjugating functional groups such as carboxylic acids ${ }^{11}$, amines $^{12}$, and alcohols ${ }^{13}$ onto $\mathrm{C}_{60}$ molecules. Grafting long chain polymers onto $\mathrm{C}_{60}$ not only improves its solubility, but also retains their unique properties of pristine $\mathrm{C}_{60}$, which is more amenable for further research. By grafting well-defined hydrophilic polymers to fullerene molecules, $\mathrm{C}_{60}$ containing water-soluble polymeric systems are obtained, and they form different nano-scale aggregates with interesting morphologies due to their amphiphilic character. ${ }^{14}$ Synthesizing novel materials by combining the unique properties of $\mathrm{C}_{60}$ and specific properties of polymers not only enhance its processability but also extend the desired end-use applications. ${ }^{15}$

The development of aggregates with different morphologies and its aggregation mechanism in solution using well-defined polymeric system are of potential interest to the research community. ${ }^{16}$ Self-assembly of $\mathrm{C}_{60}$ containing polymers possess promising end-use applications. ${ }^{17,18}$ Though a few studies have been reported on the self-assembly behavior of fullerene containing polymers in organic solvents ${ }^{14,19}$, there is a scarcity of reports describing the self-assemble behavior of welldefined fullerene containing polymers in aqueous solution. Yang and co-workers reported the synthesis and aggregation behavior of poly(acrylic acid) $b-\mathrm{C}_{60}$ in aqueous solution, which forms a core-shell structure, whose microstructure controls the photo-conductive properties. ${ }^{20}$ Over the last couple of few years, we have focused on the synthesis and self-assembly behavior of well-defined fullerene containing polymers. Recently, we have synthesized a series of well-defined stimuliresponsive $\mathrm{C}_{60}$ containing polyelectrolytes such as poly(2(dimethylamino)ethyl methacrylate) (PDMAEMA- $\left.b-\mathrm{C}_{60}\right)^{21}$ and poly(methacrylic acid) $-b-C_{60}$ (PMAA- $\left.b-C_{60}\right)^{22},{ }^{23}$ and polyampholytes such as P(MAA- $b$-DMAEMA)- $b-C_{60}{ }^{24}$ and studied their self-assembly behavior as a function of $\mathrm{pH}$ and temperature. Both PDMAEMA- $b-\mathrm{C}_{60}$ and PMAA- $b$ - 
$\mathrm{C}_{60}$ possess micellar-like aggregate at low and high $\mathrm{pH}$ respectively. We have also demonstrated the use of negatively charged aggregates of PMAA- $b-\mathrm{C}_{60}$ or PAA- $b$ $\mathrm{C}_{60}$ to induce and control the formation of fractal patterns from nano- to microscopic scales ${ }^{23}$.

The studies on the synthetic polybetaine were reviewed recently by Lowe and McCormick. ${ }^{25}$ Much interest has also been focused on the self-assembled structure of polyzwitterionic block polymers in aqueous solutions, due to their unique anti-polyelectrolyte effect i.e., chain expansion upon the addition of electrolyte (salt). ${ }^{25}$ The most interesting property of polyzwitterionic polymers is that they can be used to mimic natural occurring ampholytic polymers, such as protein near the iso-electric point (IEP) or DNA at low $\mathrm{pH}^{26}$ Their characteristics may respond to external stimuli such as temperature or ionic strength of the solution. ${ }^{27}$ In aqueous solution, these polymers self-organize into different kinds of structures, depending on the hydrophobicity of the backbone and solvent quality. At low temperatures, their solutions are cloudy due to the strong intermolecular electrostatic attractive interaction. When the temperature exceeds the upper critical solution temperature (UCST), the solution becomes clear when the thermal energy is larger than the electrostatic attraction. ${ }^{28}$

Different kinds of polyzwitterionic polymers and its copolymers have been developed and their aqueous solution properties were studied. ${ }^{29-33}$ Armes and coworkers studied the salt dependency on chain expansion of micellar aggregates produced from betainized PDMAEMA- $b$ PMMA. ${ }^{34}$ However, a detailed study on the dependence of UCST on salt concentration has not been reported. In addition, there is no reported on the study of the selfassembly behavior of well-defined $\mathrm{C}_{60}$ containing polyzwitterionic polymers. For $\mathrm{C}_{60}$ containing polyzwitterionic polymer, the chemical structure, molecular weight, polymer concentration, ionic strength and temperature play important roles in controlling the self-assembly behavior of the system. Because of the potential applications of both $\mathrm{C}_{60}$ and polyzwitterionic polymers in biological science, ${ }^{35,36}$ we synthesized such a well-defined $\mathrm{C}_{60}$ containing polysulfobetaine polymer and studied its self-assembly behavior as a function of temperature and salt concentration

\section{EXPERIMENTAL SECTION}

\section{A. Materials}

$\mathrm{C}_{60}$ (> 99.5\%) and 2-(dimethylamino)ethyl methacrylate (DMAEMA, 98\%) monomer were purchased from MTR Ltd and Sigma-Aldrich respectively. 1,1,4,7,10,10hexamethyltriethylenetetramine (HMTETA 97\%, Aldrich), $\mathrm{CuCl}$ (Aldrich 99.99\%) and p-toluene sulfonyl chloride (Fluka 99\%) were used as received. DMAEMA was passed through a basic alumina column, dried over $\mathrm{CaH}_{2}$ for overnight and then distilled under reduced pressure. All the solvents used in the synthesis were freshly distilled. For polymer solution preparation, de-ionized water used was from Millipore Alpha-Q purification system equipped with a 0.22 micron filter, while $\mathrm{HCl}, \mathrm{NaOH}$, and $\mathrm{NaCl}$ (Merck) were used to adjust $\mathrm{pH}$ and ionic strength.

\section{B. Synthesis of Betainized PDMAEMA- $b-C_{60}$ Polymer}

The synthesis of well-defined mono-end-capped $\mathrm{C}_{60}$ containing PDMAEMA polymer (PDMAEMA- $b-C_{60}$ ) was reported previously. ${ }^{21}$ The $\mathrm{M}_{\mathrm{n}}$ of the PDMAEMA- $b-\mathrm{C}_{60}$ determined from GPC was 13,000 Da with a polydispersity index (PDI) of 1.18. For the synthesis of betainized PDMAEMA- $b-C_{60}$ polymer (Bet-PDMAEMA- $b-\mathrm{C}_{60}$ ), about $4 \mathrm{~g}$ of PDMAEMA- $b-\mathrm{C}_{60}$ was solubilized in $60 \mathrm{ml}$ of THF in a $100 \mathrm{ml}$ round bottom flask equipped with a magnetic stirring bar. 1,3-propane sultone (2 equivalents to DMAEMA monomer segments) was added to the reaction mixture and the solution was stirred at room temperature for 16 hrs. During betainization, the polymer became a gel and precipitated from the solution. After the completion of the betainization reaction, THF was completely removed in a rotary evaporator and the final polymer was dried at room temperature under vacuum. Finally, excess amount of 1,3-propane sultone was removed by Soxhlet extraction using THF to yield a brown colored betainized PDMAEMA- $b-C_{60}$.

\section{Characterisation}

\section{1) $U V$-Vis}

A HP8453 UV-visible spectrophotometer equipped with a HP89090A temperature control unit was used to measure the absorption and transmittance of the polymer solutions at different temperatures and pHs. For the absorption study, the wavelength was scanned from 200 to $900 \mathrm{~nm}$, while the wavelength was set to $600 \mathrm{~nm}$ for the transmittance experiments.

2) Viscometry

The efflux time of dilute Bet-PDMAEMA and BetPDMAEMA- $b-C_{60}$ aqueous solutions with presence of different concentrations of $\mathrm{NaCl}$ was measured using an Ubbelohde capillary viscometer at $25{ }^{\circ} \mathrm{C}$ maintained with a thermostatic water bath. The measured efflux times were then converted to the relative viscosity using the following relationship

$$
\eta_{r}=\frac{t}{t_{0}}
$$

where $t$ and $t_{0}$ are the efflux times for same concentration of Bet-PDMAEMA or Bet-PDMAEMA- $b-C_{60}$ in salt solution and in water respectively. 
3) NMR Spectroscopy: The ${ }^{1} \mathrm{H}-\mathrm{NMR}$ spectrum of the BetPDMAEMA- $b-\mathrm{C}_{60}$ was measured using a Brüker DRX400 instrument in $\mathrm{D}_{2} \mathrm{O}$ at different temperatures.

4) Laser Light Scattering: A Brookhaven BI-200SM goniometer system equipped with a 532 channel BI9000AT digital multiple $\tau$ correlator was used to perform laser light scattering experiments. For static light scattering (SLS), Berry-plot was used to analyze the experimental data and the refractive index increment was measured using a BIDNDC differential refractometer. For dynamic light scattering (DLS), the inverse Laplace transform of REPES in the Gendist software package was used to analyze time correlation functions with probability of reject setting at 0.5 . A $0.2 \mu \mathrm{m}$ filter was used to remove dust prior to light scattering experiments and the experimental temperature was controlled by a PolyScience water-bath.

5) Transmission Electron Microscopy (TEM): Transmission electron microscopic studies were conducted using a JEOL JEM-2010 transmission electron microscope operating at an accelerate voltage of $200 \mathrm{kV}$. The carbon pre-coated copper gird was placed on a filter paper. For the TEM samples in the absence of salt (above UCST), 0.2 wt\% polymer solution was heated to $40{ }^{\circ} \mathrm{C}$ and a drop of solution was placed on a copper grid which was thermostated at $40{ }^{\circ} \mathrm{C}$ in an oven. For the TEM sample in presence of salt, a drop of Bet-PDMAEMA- $b-\mathrm{C}_{60}$ in $0.5 \mathrm{M}$ $\mathrm{NaCl}$ solution was placed on a copper grid and allowed to dry overnight at room temperature.

\section{RESULTS AND DISCUSSION}

The synthesis and characterization of the well-defined PDMAEMA- $b-C_{60}$ has been reported previously. ${ }^{21}$ The typical synthesis route for the Bet-PDMAEMA- $b-\mathrm{C}_{60}$ is shown in Scheme 1. Since the DMAEMA segment was highly reactive towards quaternization, selective betainization of PDMAEMA was achieved at ambient temperature using 1,3-propane sultone in $\mathrm{THF}^{34}$ After complete betainization, gelation occurs at room temperature since the product is not soluble in THF. It has been demonstrated that under mild condition of betainization, chain scission was not possible. Hence, the narrow polydispersity of the polymer is retained in the resulting Bet-PDMAEMA- $b-\mathrm{C}_{60}$ system. The extent of betainization was calculated using ${ }^{1} \mathrm{H}-\mathrm{NMR}$ spectrum (Figure 1) measured in presence of $0.5 \mathrm{M} \mathrm{NaCl}$ in $\mathrm{D}_{2} \mathrm{O}$. From the relative peak intensities at $3.31 \mathrm{ppm}$ (corresponds to the $-\mathrm{N}\left(\mathrm{CH}_{3}\right)_{2}$ protons of DMAEMA segments) and at $3.05 \mathrm{ppm}$ (corresponds to $-\mathrm{CH}_{2} \mathrm{SO}_{3}^{-}$protons of 1,3propane sultone segments), the extent of betainization was calculated to be more than $96 \%$. The betainized polymer reported is the first example of mono-substituted welldefined $\mathrm{C}_{60}$ containing sulfopropylbetine polymer (BetPDMAEMA-b- $\left.\mathrm{C}_{60}\right)$.
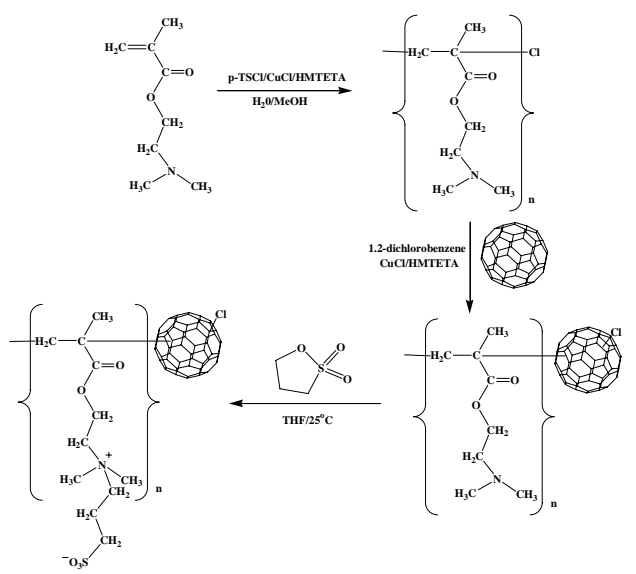

Scheme 1.Synthesis scheme of Bet-PDMAEMA- $b-\mathrm{C}_{60}$

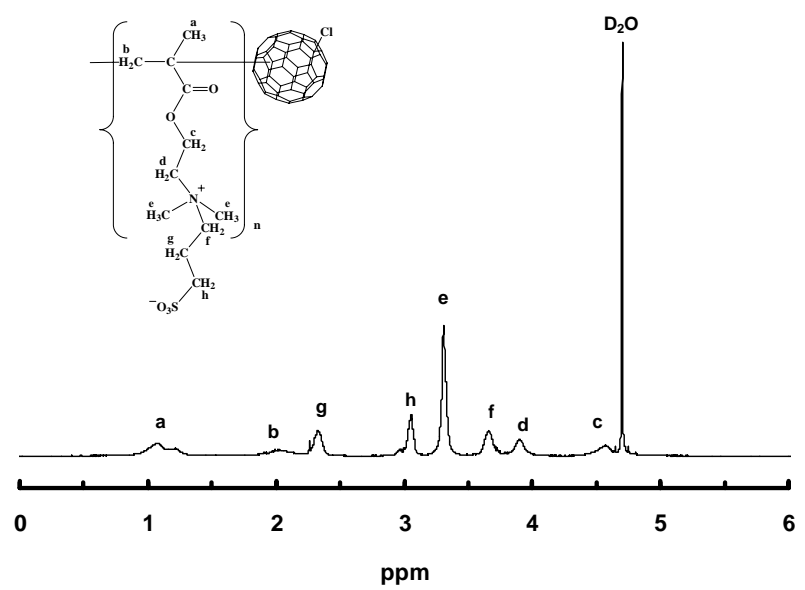

Fig. $1 .{ }^{1} \mathrm{H}-\mathrm{NMR}$ spectrum of Bet-PDMAEMA- $b-\mathrm{C}_{60}$ in $\mathrm{D}_{2} \mathrm{O}$ in presence of $0.5 \mathrm{M} \mathrm{NaCl}$

\section{A. Temperature Dependence of Solubility}

At room temperature, Bet-PDMAEMA- $b-C_{60}$ was water-insoluble due to strong electrostatic attractive force from oppositely charged ion pairs along the polymer chains. When the temperature was increased to a critical value where the thermal energy is sufficient in overcoming the electrostatic attractive force, Bet-PDMAEMA- $b$ - $C_{60}$ becomes water-soluble at a temperature that is referred to as the UCST. The solubility of both Bet-PDMAEMA- $b-\mathrm{C}_{60}$ and Bet-PDMAEMA as a function of temperature was examined and compared by light transmittance study using a UV-visible spectrophotometer at a fixed wavelength of $600 \mathrm{~nm}$. Figure 2 compares the light transmittances of 0.1 $w t \%$ Bet-PDMAEMA- $b-C_{60}$ and Bet-PDMAEMA in water over a temperature range of 20 to $50{ }^{\circ} \mathrm{C}$. From the figure, it was evident that aqueous Bet-PDMAEMA solution is transparent over the experimental temperature range, indicating that its UCST is lower than $20^{\circ} \mathrm{C}$, which agrees with the reported UCST of less than $15{ }^{\circ} \mathrm{C} .{ }^{28}$ However, Bet-PDMAEMA- $b-\mathrm{C}_{60}$ exhibits a much higher UCST, thus it is water-insoluble at room temperature. With increasing temperature, the yellowish turbid solution turns yellowish translucent solution and the UCST of Bet-PDMAEMA- $b$ - 
$\mathrm{C}_{60}$ in water was determined to be $\sim 32{ }^{\circ} \mathrm{C}$. Attachment of hydrophobic moiety to Bet-PDMAEMA alters the phase behavior to yield a higher UCST. However, the transition of Bet-PDMAEMA- $b-\mathrm{C}_{60}$ was found to be broad when compared to the LCST of PDMAEMA- $b-\mathrm{C}_{60}$ where the transition is very sharp. Generally, the transition for UCST is broader than LCST as the former is driven by enthalpic effect such as the disruption of solute-solute electrostatic interaction, while the later is controlled by entropic effect, such as the disruption of $\mathrm{H}$-bonds and water structures.

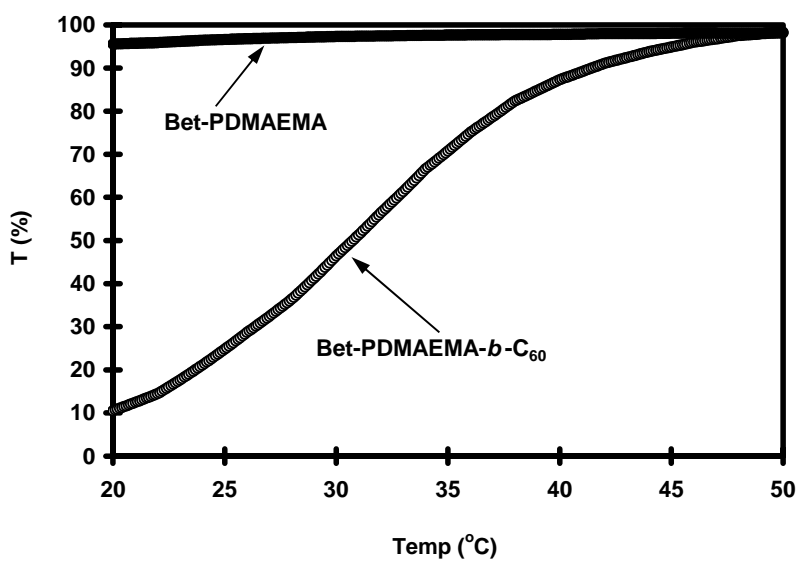

Fig. 2. Light transmittance of Bet-PDMAEMA and Bet-PDMAEMA- $b$ $\mathrm{C}_{60}$ at different temperatures

The phase behavior of Bet-PDMAEMA- $b-C_{60}$ polymer and the UCST was further confirmed by conducting ${ }^{1} \mathrm{H}-$ NMR spectroscopic studies at different temperatures. Figure 3 shows the ${ }^{1} \mathrm{H}-\mathrm{NMR}$ spectrum of BetPDMAEMA- $b-\mathrm{C}_{60}$ in $\mathrm{D}_{2} \mathrm{O}$ solution measured at different temperatures. At $20^{\circ} \mathrm{C}$, all the peaks corresponding to BetPDMAEMA segments, such as the signals at 0.85-1.1 ppm (back bone $\left.-\underline{\mathrm{CH}}_{3}\right), 2.14 \mathrm{ppm}\left(-\mathrm{CH}_{2} \mathrm{CH}_{2} \mathrm{SO}_{3}{ }^{-}\right), 2.85 \mathrm{ppm}$ ($\left.\mathrm{CH}_{2} \mathrm{SO}_{3}{ }^{-}\right), 3.66 \mathrm{ppm}\left(-\mathrm{COOCH}_{2} \underline{\mathrm{H}}_{2}-\mathrm{N}^{+}-\right), 3.44 \mathrm{ppm}(-$ $\mathrm{N}+\mathrm{CH}_{2} \mathrm{CH}_{2} \mathrm{CH}_{2^{-}}$), and $4.33 \mathrm{ppm}\left(-\mathrm{COOC} \underline{\mathbf{H}}_{2}^{-}\right)$were less pronounced. This indicates that large fractions of BetPDMAEMA segments are in the de-solvated or collapsed state (less mobile) due to the strong intermolecular electrostatic attraction. However, small amounts of BetPDMAEMA segments are exposed in water as solvated layer around the compact Bet-PDMAEMA surface, which can be observed from the ${ }^{1} \mathrm{H}-\mathrm{NMR}$ spectra. When the solution temperature was increased at an interval of $5{ }^{\circ} \mathrm{C}$, the magnitude of the peaks corresponding to BetPDMAEMA segments is increased, corresponding to increasing proportions of mobile and solvated BetDMAEMA segments. At temperature beyond the UCST (35 ${ }^{\circ} \mathrm{C}$ ), where the thermal energy is sufficiently high in overcoming the electrostatic attraction, Bet-PDMAEMA- $b$ $\mathrm{C}_{60}$ becomes water-soluble. All the signals corresponding to Bet-PDMAEMA segments in the ${ }^{1} \mathrm{H}-\mathrm{NMR}$ spectra showed a pronounced maximum and they shifted towards a lower field, confirming that the Bet-PDMAEMA segments are completely solvated (mobile).

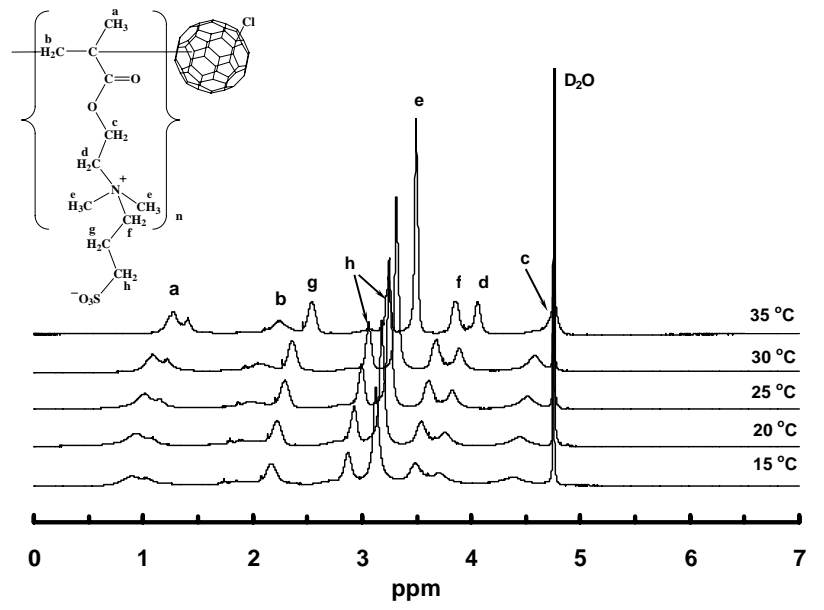

Fig. 3. ${ }^{1} \mathrm{H}-\mathrm{NMR}$ spectra of Bet-PDMAEMA- $b-\mathrm{C}_{60}$ in $\mathrm{D}_{2} \mathrm{O}$ measured at different temperatures

\section{B. Phase Behavior in the Presence of Salt.}

Due to the zwitterionic property of Bet-PDMAEMA- $b$ $\mathrm{C}_{60}$, the presence of salt will alter the phase behavior of the polymer in aqueous solution. Figure 4 shows the UCST of Bet-PDMAEMA- $b-\mathrm{C}_{60}$ in aqueous solution as a function of $\mathrm{NaCl}$ concentration. The UCST of Bet-PDMAEMA- $b-\mathrm{C}_{60}$ increases initially in the low salt concentration regime. In absence of salt, the UCST of the polymer was determined to be $32{ }^{\circ} \mathrm{C}$, and it increases to a maximum of $49{ }^{\circ} \mathrm{C}$ at 0.35 wt $\% \mathrm{NaCl}$, and then decreases again with increasing salt concentration. The observation is supported by viscometric and light transmittance studies. The insert in Figure 4 shows the $\mathrm{NaCl}$ concentration dependence of the relative viscosity of $0.3 \mathrm{wt} \%$ Bet-PDMAEMA- $b-\mathrm{C}_{60}$ and BetPDMAEMA at $25{ }^{\circ} \mathrm{C}$ respectively. During the sample preparation, it is evident that the solution is very cloudy in the presence of $0.05 \mathrm{wt} \%$ of $\mathrm{NaCl}$, which indicates the negative value of $\mathrm{A}_{2}$. As $\mathrm{NaCl}$ concentration less than 0.05 $w t \%$, relative viscosity of the solution decreases slightly or unchanged, which indicates the addition of salt could shield electrostatic interaction but the effect is not significant. However, with further increasing salt concentration, both relative viscosity and solubility enhanced. The reduced viscosity and $A_{2}$ values increased with the increase in salt concentration has been reported for other ampholytical polymers. ${ }^{37}$ For Bet-PDMAEMA- $b-\mathrm{C}_{60}$ in solution at temperatures below the UCST, the intermolecular electrostatic attraction between oppositely charged ion pairs produces a compact chain conformation, and this strong inherent energy makes the polymer not soluble in aqueous solution. However, there are small amount of the ion pairs exposed in bulk water due to its zwitterionic property (Figure 5). With the addition of small amount of salt, could bind onto these exposed ion pairs. As a result, the polymer chains shrink similar to that of salt addition to polyelectrolyte solution, which not only 
facilitates increasing proportion of inter-molecular electrostatic interaction but also decreases the solubility of zwitterionic polymers in water. Since the UCST is related to the thermal energy required to overcome electrostatic attraction, the UCST of the polymer in the presence of small amounts of salt is greater than that in the absence of salt. When the salt concentration reaches a critical limit (when all the exposed ions are saturated by small ions), a maximum in the UCST was observed corresponding to the thermal energy required to overcome the strong electrostatic attraction forces. Further increase in the salt concentration $(>0.35 \mathrm{wt} \% \mathrm{NaCl}$ ) results in the shielding of intermolecular electrostatic attraction, which facilitates the dissolution of polymer chains. This behavior is commonly referred to as the "anti-polyelectrolyte" behavior of polyampholytes. Hence, less thermal energy is required to negate the intermolecular electrostatic attraction in the presence of excess amounts of salt, which is reflected by the reduction in the UCST.

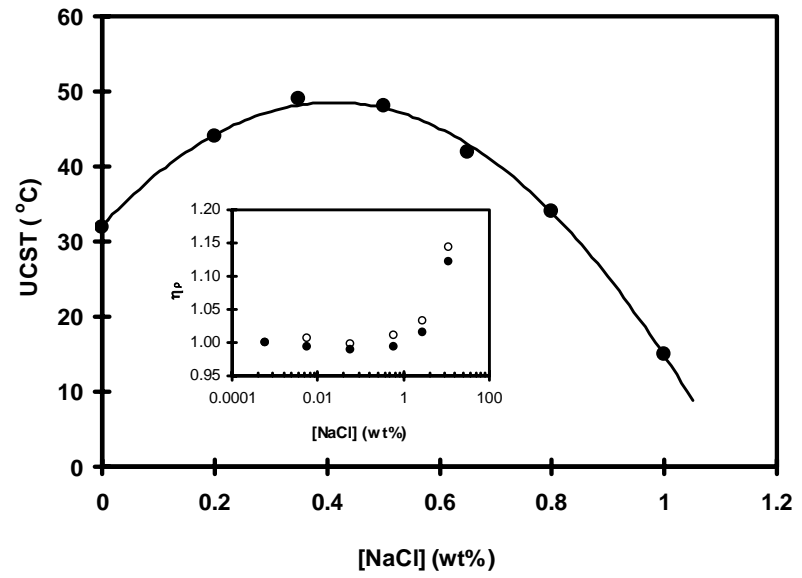

Fig. 4 . The effect of salt on the UCST of Bet-PDMAEMA- $b-C_{60}$. The insert shows the $\mathrm{NaCl}$ concentration dependence of the relative viscosity of $0.3 \mathrm{wt} \%$ Bet-PDMAEMA- $b-\mathrm{C}_{60}$ (filled circle) and Bet-PDMAEMA (open circle) respectively

At temperature beyond the UCST, the polymer exists as an extended coil in dilute aqueous solution instead of compact structure observed below the UCST. The effect of salt on the hydrodynamic radius of betainized PDMAEMA homopolymer was reported by Armes and co-workers, where they reported that the hydrodynamic radius increased with increasing salt concentration, and this phenomenon was explained on the basis of the antipolyelectrolyte effect. ${ }^{34}$. We report for the first time the UCST of Bet-PDMAEMA- $b-C_{60}$ in aqueous solution as a function of salt concentration. It is evident that in the presence of lower concentrations of salt, the betainized polymer exhibits "polyelectrolyte" behavior where UCST increases with the addition of $\mathrm{NaCl}$. However, after a critical salt concentration, the betainized polymer displayed an "anti-polyelectrolyte" character where the UCST decreases with increasing $\mathrm{NaCl}$ concentration.
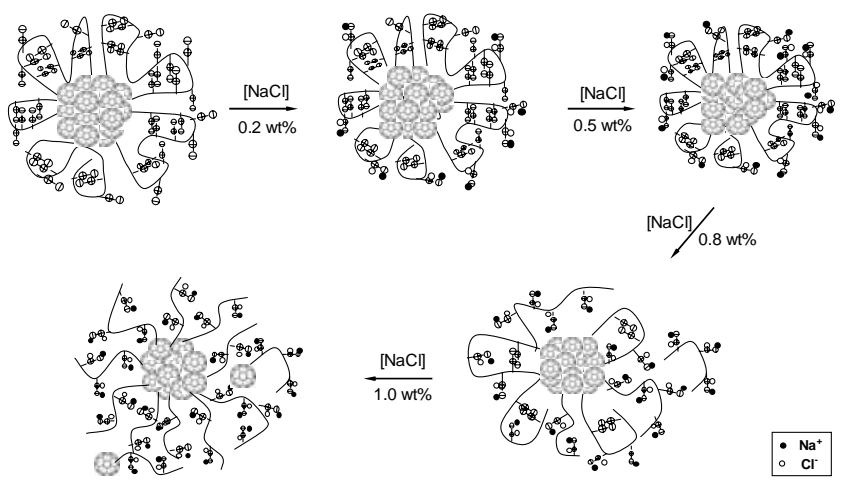

\begin{tabular}{r|r|}
$\mathrm{Na}^{+}$ \\
$\mathrm{Cl}$
\end{tabular}

Fig. 5. Schematic representation of the behavior of Bet-PDMAEMA- $b-\mathrm{C}_{60}$ in the presence of different concentrations of $\mathrm{NaCl}$

\section{Self-assembly behavior of Bet-PDMAEMA- $b-C_{60}$.}

Betainized polymers are soluble only in aqueous salt solution and at temperature greater than the UCST. Since Bet-PDMAEMA- $b-\mathrm{C}_{60}$ is soluble in $0.5 \mathrm{M} \mathrm{NaCl}$ aqueous solution at room temperature, its self-assembly behavior was examined and discussed in this section. Addition of $\mathrm{NaCl}$ not only decreases the intermolecular attractive interaction but also shields the electrostatic repulsive interaction between charged segments, imparting enhanced
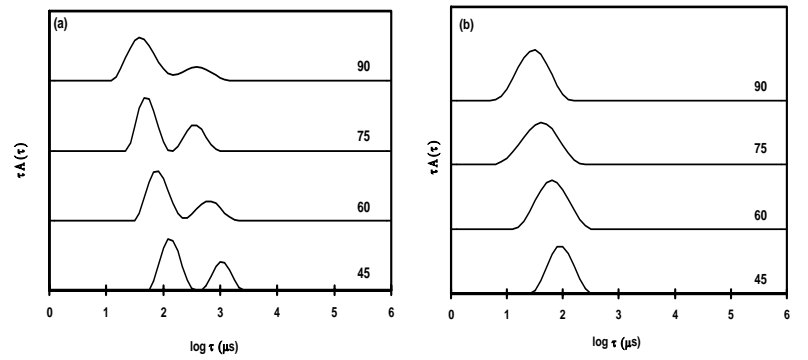

Fig. 6. Decay time distribution functions of $0.2 \mathrm{wt} \%$ of Bet-PDMAEMA$b-\mathrm{C}_{60}(\mathrm{a})$ and Bet-PDMAEMA (b) measured at $25^{\circ} \mathrm{C}$

chain flexibility of Bet-PDMAEMA segments. Since laser light scattering is a versatile research tool to study $C_{60}$ containing amphiphiles ${ }^{38}$, the solution behaviors of both Bet-PDMAEMA and Bet-PDMAEMA- $b-\mathrm{C}_{60}$ were studied by laser light scattering. Figure 6 (a \& b) shows typical decay time distribution functions of 0.1 wt\% BetPDMAEMA- $b-C_{60}$ and Bet-PDMAEMA solution at different scattering angles. Although Bet-PDMAEMA revealed a mono-modal distribution, a bimodal distribution was observed from the decay time distribution of BetPDMAEMA- $b-C_{60}$. The dependence of decay rate $\Gamma$ on $q^{2}$ was examined, where $\mathrm{q}$ is the scattering vector ( $q=\frac{4 \pi n \sin (\theta / 2)}{\lambda}$, where $n$ is the refractive index of 
the solvent, $\theta$ is the scattering angle and $\lambda$ is the wavelength of the incident laser light in vacuum), are shown in Figure 7. A linear dependence of $\Gamma$ on $\mathrm{q}^{2}$ indicates that both decays are related to translational diffusion, suggesting the coexistence of two types of scattering objects in solution. The translational diffusion coefficients $\mathrm{D}$ can be determined from the slopes of decay rate $\Gamma$ and $\mathrm{q}^{2}$.

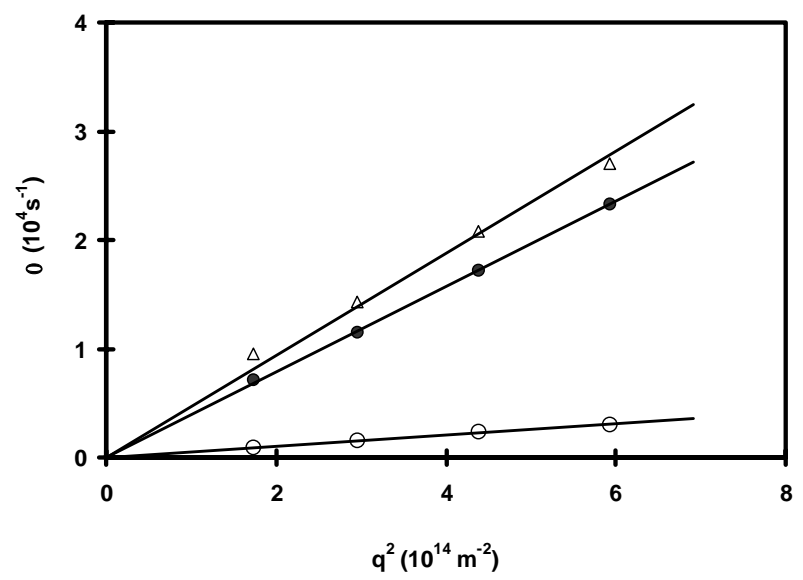

Fig. 7.Dependence of the decay rate $\Gamma$ on the square of the scattering vector $\left(q^{2}\right)$ for 0.2 wt $\%$ Bet-PDMAEMA- $b-C_{60}$ (filled circles for fast mode and open circles for slow mode) and Bet-PDMAEMA (triangles)

DLS measurements were conducted on different polymer concentrations $(0.2,0.4,0.6,0.8,1.0 \mathrm{wt} \%)$ in the presence of $0.5 \mathrm{M} \mathrm{NaCl}$ to examine the concentration dependence of the diffusion coefficients. It is evident from Figure 8 that both diffusion coefficients are independent of polymer concentration, which indicates that Bet-PDMAEMA- $b-\mathrm{C}_{60}$ aggregates are produced in solution via the closed association mechanism. By extrapolating the diffusion coefficients to zero concentration, the diffusion coefficients in the infinite dilute solution $\mathrm{D}_{0}$ were determined. The hydrodynamic radius of the scattering objects can be determined using the Stokes-Einstein relationship;

$$
R_{h}=\frac{k_{B} T}{6 \pi \eta D_{0}}
$$

where $k_{B}$ is the Boltzmann constant, $q$ is the scattering vector, and $\eta$ is the solvent viscosity. From the DLS results performed at different scattering angles and different concentrations, the $\mathrm{R}_{\mathrm{h}}$ values of fast and slow modes are found to be $\sim 6$ and $\sim 47 \mathrm{~nm}$ respectively. Based on the polymer molecular weight and theoretically calculated $R_{h}$ values, the fast mode is most likely to correspond to unimers, while the $\mathrm{R}_{\mathrm{h}}$ of the large particles (slow mode) corresponds to either non-equilibrium aggregates or micelles comprising the hydrophobic $\mathrm{C}_{60}$ core and solvated Bet-PDMAEMA corona. However, the 0.1 wt\% BetPDMAEMA homopolymer in $0.5 \mathrm{M} \mathrm{NaCl}$ solution possesses a unimodal distribution in the decay time distribution function. The $\mathrm{R}_{\mathrm{h}}$ determined from decay time distribution function is $\sim 5 \mathrm{~nm}$, which corresponds to BetPDMAEMA unimers in agreement with the fast mode determined for $0.1 \mathrm{wt} \%$ Bet-PDMAEMA- $b-\mathrm{C}_{60}$ solution. This reinforces the observation that hydrophobic $\mathrm{C}_{60}$ in Bet-PMAEMA- $b-C_{60}$ influences the formation of nonequilibrium aggregates or micelles in solution.

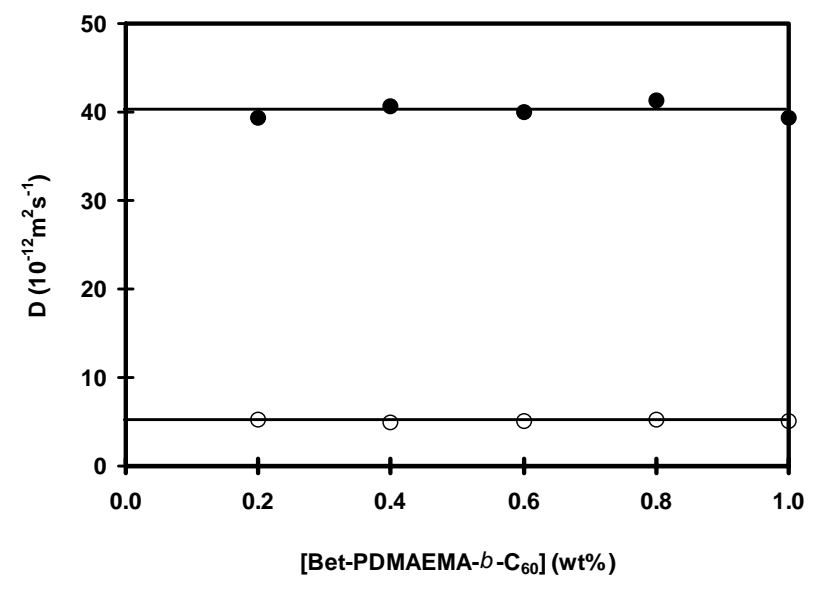

Fig. 8. Concentration dependence of Bet-PDMAEMA- $b-C_{60}$ hydrodynamic radius diffusion coefficients, where the filled circles are the fast decay mode and the open circles are the slow decay mode

Static light scattering was also performed to further elucidate the aggregation behavior of Bet-PDMAEMA- $b$ $\mathrm{C}_{60}$ in $0.5 \mathrm{M} \mathrm{NaCl}$ solution. Using SLS, one can determine the $\mathrm{z}$-averaged radius of gyration $\left(\mathrm{R}_{\mathrm{g}}\right)$ and weight averaged molecular weight $\mathrm{M}_{\mathrm{w}}$ of the particles in solution. Due to the strong solvent and solute interaction, Berry-plot was used to determine the weight-averaged molecular weight $\mathrm{M}_{\mathrm{w}}, \mathrm{A}_{2}$ and $\mathrm{R}_{\mathrm{g}}$.

$$
\left(\frac{K C}{R_{\theta}}\right)^{0.5}=\left(\frac{1}{M_{w}}\right)^{0.5}\left(1+\frac{1}{6} q^{2} R_{g}^{2}\right)\left(1+A_{2} M_{w} C\right)
$$

where $\mathrm{K}\left(=4 \pi^{2} n^{2}(\mathrm{dn} / \mathrm{dC})^{2} / \mathrm{N}_{\mathrm{A}} \lambda^{4}\right)$ is an optical constant with $\mathrm{N}_{\mathrm{A}}, \mathrm{n}$, and $\lambda$ being the Avogadro's number, the solvent refractive index, and the wavelength of the light in vacuum, respectively. $\mathrm{dn} / \mathrm{dC}$ is the refractive index increment of the polymer solution obtained from a differential refractometer, $\mathrm{C}$ is the polymer concentration, $\mathrm{R}_{\theta}$ is the excess Rayleigh ratio, $\mathrm{M}_{\mathrm{w}}$ is the weight-averaged molar mass, and $\mathrm{R}_{\mathrm{g}}$ is root-mean square $\mathrm{z}$-averaged radius of gyration. $A_{2}$ is the second viral coefficient, and $q$ is the scattering wave vector. The values of the refractive index increment dn/dC of Bet-PDMAEMA- $b-\mathrm{C}_{60}$ in the $0.5 \mathrm{M}$ $\mathrm{NaCl}$ determined from BI-DNDC differential refractometer and found to be $0.126 \mathrm{~g} / \mathrm{ml}$. Figure 9 shows the typical Berry-plot for the Bet-PDMAEMA- $b-C_{60}$. The slight curvature in the Berry Plot is probably related to the bimodal distribution of unimers and aggregates in solution or associated with the contribution of $P(q)$ and $S(q)$ from the large aggregate in solution. The apparent weight- 
averaged molecular weight $\mathrm{M}_{\mathrm{w}}$ was determined to be $1.60 \times 10^{5} \mathrm{~g} / \mathrm{mol}$. Thus, the averaged aggregation number could be determined by the quotient of the aggregate $M_{w}$ and the unimer $\mathrm{M}_{\mathrm{w}}$. Since there are two types of particles in solution and the percentage of the unimers can be determined from DLS, it is found that the aggregation number $\mathrm{N}_{\mathrm{agg}}$ of the aggregates was about $25 .{ }^{39}$ At the same time, the $\mathrm{z}$-averaged radius of gyration $\left(\mathrm{R}_{\mathrm{g}}\right)$ was found to be $\sim 42 \mathrm{~nm}$, but it is more sensitive to large particles in solution. From the definition of $\mathrm{R}_{\mathrm{g}}$, the $\mathrm{R}_{\mathrm{g}}$ of the large particle can be determined based on the following relationship,

$$
R_{g}^{2}=\frac{\sum n_{i} M_{i}^{2}\left(R_{g}^{2}\right)_{i}}{\sum n_{i} M_{i}^{2}}
$$

It was found that the $R_{g}$ of aggregates to be $43.5 \mathrm{~nm}$. Combining with DLS data, the ratio of $\mathrm{R}_{\mathrm{g}} / \mathrm{R}_{\mathrm{h}}$ was found to be $\sim 0.93$ and this value is related to the micelles with a more compact structure. This is further supported by the fractal dimension measurement.

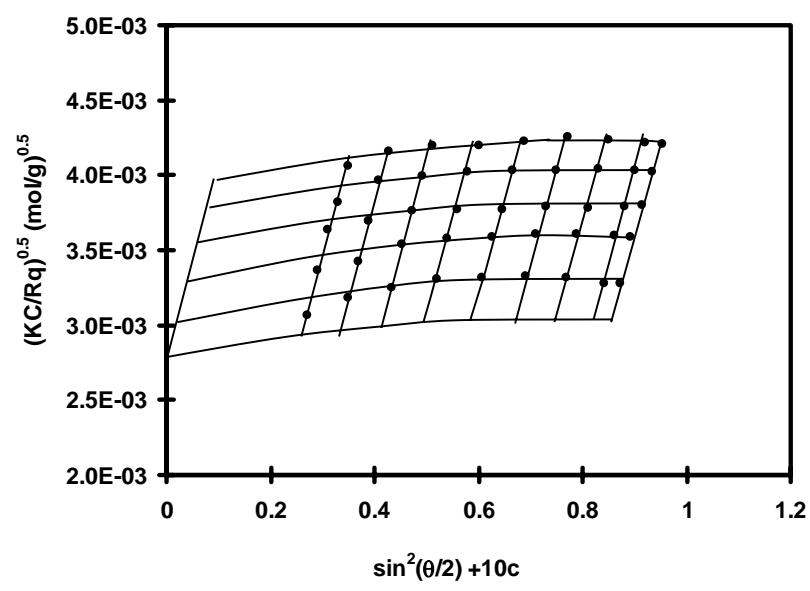

Fig. 9. Typical Berry plot of Bet-PDMAEMA-b- $\mathrm{C}_{60}$ at room temperature in $0.5 \mathrm{M} \mathrm{NaCl}$ aqueous solution

\section{D) Transmission Electron Microscopy}

To further elucidate the aggregation behavior of BetPDMAEMA- $b-\mathrm{C}_{60}$, morphological study was carried out using the transmission electron microscope (TEM). Figure 10 shows the TEM images of Bet-PDMAEMA- $b-\mathrm{C}_{60}$ polymer above the UCST $\left(\sim 35^{\circ} \mathrm{C}\right.$, in absence of salt) and in presence of $0.5 \mathrm{M} \mathrm{NaCl}$ solution at room temperature. Abundance of spherical aggregates in the form of clusters was obtained in the absence of salt above the UCST (Figure 10a). Due to the rapid drying process, the changes in the surface tension caused the spherical aggregates to agglomerate to form clusters. Since the dehydration process takes place while drying, the radii of small spherical aggregates were found to be $\sim 35 \mathrm{~nm}$, which is smaller than the $\mathrm{R}_{\mathrm{h}}$ determined from DLS. In the presence of salt at temperature below the UCST, the formation of interesting fractal pattern at the sub-micron range was observed (Figure 10b). Such controlled fractal morphology was observed for neutralized PMAA- $b-\mathrm{C}_{60}$ but not for PDMAEMA- $b-\mathrm{C}_{60}$ in salt solution. The negative charges on the surface of large compound micelle (LCM) for the PMAA- $b-\mathrm{C}_{60}$ in salt solution are critical to the fractal growth process, ${ }^{23}$ where the LCMs act as nucleating sites for the crystallization of $\mathrm{NaCl}$ to produce the controlled fractal pattern. In the case of Bet-PDMAEMA- $b-\mathrm{C}_{60}$ in salt solution, the sodium ions are condensed on the negatively charged surface $\left(-\mathrm{SO}_{3}{ }^{-} \mathrm{Na}^{+}\right)$of the micelle and each micelle acts as nucleating site that controls the crystallization of $\mathrm{NaCl}$. We also performed TEM on the Bet-PDMAEMA in $\mathrm{NaCl}$ solution and no fractal pattern was observed, instead only $\mathrm{NaCl}$ crystals were observed. This further reinforced the importance of $\mathrm{C}_{60}$ core, which acts as a nucleating agent in the production of the fractal structure. The progressive diffusion control growth of sodium chloride crystals during the drying process produces the nano-scale fractal patterns shown in Figure 10b.

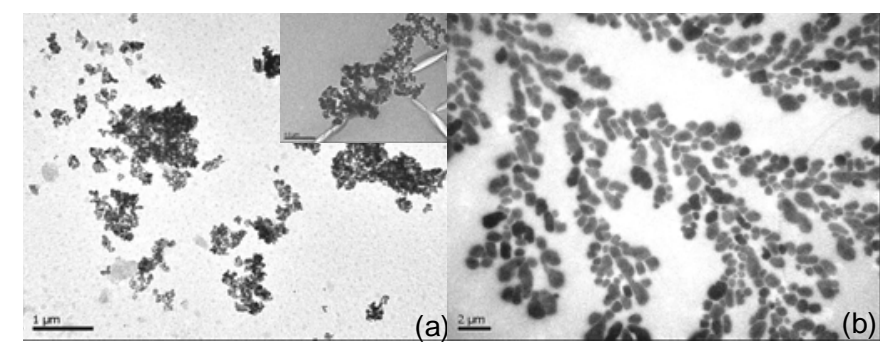

Fig. 10. TEM micrographs of $0.2 \mathrm{wt} \%$ Bet-PDMAEMA- $b-\mathrm{C}_{60}$ in aqueous solution (a) in absence of salt (above UCST); (b) in presence of $0.5 \mathrm{M}$ $\mathrm{NaCl}$

\section{CONCLUSIONS}

A well-defined PDMAEMA- $b-C_{60}$ was synthesized using ATRP and betainized with 1, 3-sulfobetaine to yield BetPDMAEMA- $b-\mathrm{C}_{60}$. Blocking of $\mathrm{C}_{60}$ to Bet-DMAEMA increases the UCST of the polymer in aqueous media. The presence of salt shifts the UCST of Bet-PDMAEMA- $b-C_{60}$ aqueous solution. At lower electrolyte concentrations, the UCST of the polymer increases with salt concentration due to the binding of small electrolyte onto the exposed surface of the ions. At the critical electrolyte concentration, the UCST of the polymer starts to decrease due to the "antipolyelectrolyte" effect. Bet-PDMAEMA- $b-\mathrm{C}_{60}$ is soluble in $0.5 \mathrm{M} \mathrm{NaCl}$ aqueous solution at room temperature, however, they self-assemble to form micelle in aqueous solution with the hydrodynamic size of $\sim 47 \mathrm{~nm}$, coexisting with large amount of Bet-PDMAEMA- $b$ - $C_{60}$ unimers in solution. The TEM micrograph shows the formation of controlled fractal pattern morphology in presence of aqueous salt solution when dried. The utility of such templating and patterning methodology will be further 
extended to other salt systems and this can potentially be exploited for many biomedical applications.

\section{ACKNOWLEDGMENT}

We would like to acknowledge the financial supports provided by the Singapore-MIT Alliance and Ministry of Education, Singapore

\section{References}

[1] Wei, Y.; Tian, J.; MacDiamid A. J..; Masters, J. G.; Smith, A. L.; Li. D., "Preparation and conductivities of fullerene-doped polyanilines", J. Chem. Soc. Chem. Commun. 1993, pp 603-604.

[2] Jehoulet, C.; Bard, A. J.; Wudl, F., "Electrochemical reducyion and oxidation of C60 films", J. Am. Chem. Soc. 1991, vol 113, pp 5456-5457.

[3] Deguchi, S.; Alargov, R. G.; Tsuji, K., "Stable dispersions of fullerenes, C-60 and C-70, in water. Preparation and characterization”,_Langmuir 2001, vol 17, pp 6013-6017.

[4] Martin, N.; Sanchez, L; Liescas, B.; Perez, I., " $\mathrm{C}_{60}$-Based Electroactive Organofullerenes', Chem. Rev. 1998, vol 98, pp 2527-2548.

[5] Diederich, F.; Thilgen, C., "Covalent fullerene chemistry", Science 1996, vol 271, pp 317-323.

[6] Geckeler, K. E.; Samal, S., "Syntheses and properties of macromolecular fullerenes, a review”, Polym. Int. 1999, vol 48, pp 743.

[7] Jin, H.; Chen, W. Q.; Tang, X. W.; Chiang, L. Y.; Yang, C. Y.; Schloss, J. V.; Wu, J. Y., "Polyhydroxylated C-60, fullerenols, as glutamate receptor antagonists and neuroprotective agents", J. Neurosci. Res. 2000, vol 62, pp 600-607.

[8] Chen, I. W.; Lin, A. T.; Don, D. L .; Kanakamma, P. P.; Shen, C. K. F.; Luh, T. Y.; Hwang, K. C., " $\mathrm{C}_{60}$ and Water-Soluble Fullerene Derivatives as Antioxidants Against Radical-Initiated Lipid Peroxidation”, J. Med. Chem. 1999, vol 2, pp 4614-4620.

[9] Filippone, S.; Heimann, F.; Rassat, A., "A highly water-soluble 2 : 1 beta-cyclodextrin-fullerene conjugate", Chem. Commun. 2002, pp 1508-1509.

[10] Samal, S.; Geckeler, K. E., "Cyclodextrin-fullerenes: a new class of water-soluble fullerenes”, Chem. Commun. 2000, pp 11011102

[11] Cerar, J.; Skerjanc, J. "Water-Soluble Fullerenes. 3. Alkali Salts of Fullerenehexamalonic Acid $T_{h}-\mathrm{C}_{66}(\mathrm{COOH})_{12}$ ”, J. Phys. Chem. B 2003, vol 10, pp 8255-8259.

[12] Richardson, C. F.; Schuster, D. I.; Wilson, S. R., "Synthesis and Characterization of Water-Soluble Amino Fullerene Derivatives", Org. Lett. 2000, vol 2, pp 1011-1014.

[13] Chiang, L. Y.; Bhonsle, J. B.; Wang, L.; Shu, S. F.; Chang, T. M.; Hwu, J. R., "Efficient one-flask synthesis of water-soluble [60]fullerenols”, Tetrahedran 1996, vol 52, pp 4963-4972.

[14] Tan, C. H.; Ravi, P.; Dai, S.; Tam, K. C.; Gan, L. H "SolventInduced Large Compound Vesicle of [60]Fullerene Containing Poly(tert-butyl methacrylate)”, Langmuir 2004, vol 20, pp 98829884.

[15] Goswami, T. H.; Singh, R.; Alam, S.; Mathur, G. N., “ One-Pot Synthesis of a Novel Water-Soluble Fullerene-Core Starlike Macromolecule via Successive Michael and Nucleophilic Addition Reaction”, Chem. Mater. 2004, vol 16, pp 2442-2448

[16] Riegel, I. C.; Eisenberg, A., "Novel Bowl-Shaped Morphology of Crew-Cut Aggregates from Amphiphilic Block Copolymers of Styrene and 5-( $N, N$-Diethylamino)isoprene”, Langmuir 2002, vol 18, pp 3358-3363.

[17] Sitharaman, B.; Asokan, S.; Rusakova, I.; Wong, M. S.; Wilson, L. J., "Nanoscale Aggregation Properties of Neuroprotective Carboxyfullerene $\left(\mathrm{C}_{3}\right)$ in Aqueous Solution”, Nano Lett. 2004, vol 4, pp 1759-1762.
[18] Sitharaman, B.; Bolskar, R. D.; Rusakova, I.; Wilson, L. J. $\mathrm{Gd} @ \mathrm{C}_{60}\left[\mathrm{C}(\mathrm{COOH})_{2}\right]_{10}$ and $\quad \mathrm{Gd} @ \mathrm{C}_{60}(\mathrm{OH})_{x}$, "Nanoscale Aggregation Studies of Two Metallofullerene MRI Contrast Agents in Aqueous Solution”,. Nano Lett. 2004, vol 4, pp 23732378.

[19] Wang, X.; Goh, S. H.; Lu, Z. H.; Lee, S. Y. Wu, C., "LightScattering Characterization of Fullerene-Containing Poly(alkyl methacrylate)s in THF.”, Macromolecules 1999, vol 32, pp 27862788.

[20] Yang, J.; Li, L.; Wang, C., "Synthesis of a Water Soluble, Monosubstituted $\mathrm{C}_{60}$ Polymeric Derivative and Its Photoconductive Properties”, Macromolecules 2003, vol 36, pp 6060-6065

[21] Dai, S.; Ravi, P.; Tan, C. H.; Tam, K. C., "Self-Assembly Behavior of a Stimuli-Responsive Water-Soluble [60]FullereneContaining Polymer", Langmuir 2004, vol 20, pp 8569-8575.

[22] Ravi, P.; Dai, S.; Tan, C. H.; Tam, K. C., "Self-Assembly of Alkali-Soluble [60]Fullerene Containing Poly(methacrylic acid) in Aqueous Solution”, Macromolecules 2005, vol 38, pp 933939.

[23] Tan, C. H.; Ravi, P.; Dai, S.; Tam, K. C., "Polymer-Induced Fractal Patterns of [60]Fullerene Containing Poly(methacrylic acid) in Salt Solutions”, Langmuir 2004, vol 20, pp 9901-9904.

[24] Teoh, S. K.; Ravi, P.; Dai, S.; Tam, K. C., "Self-Assembly of Stimuli-Responsive Water-Soluble [60]Fullerene End-Capped Ampholytic Block Copolymer”, J. Phys. Chem. B. 2005, vol 109, pp 4431-4438.

[25] Lowe, A. B.; McCormick, C. L., "Synthesis and Solution Properties of Zwitterionic Polymers”, Chem. Rev. 2002, vol 102, pp 4177-4190.

[26] Favresse, P.; Laschewsky, A. "Synthesis and investigation of new amphiphilic poly(carbobetaine)s made from diallylammonium monomers”, Polymer 2001, vol 42, pp 27552766.

[27] Kudaibergenov, S. E., "Recent advances in the study of synthetic polyampholytes in solutions”, Adv. Polym. Sci. 1999, vol 144, pp 115-197.

[28] Weaver, J. V. M.; Armes, S. P.; Butun, V.., "Synthesis and aqueous solution properties of a well-defined thermo-responsive schizophrenic diblock copolymer”, Chem. Commun. 2002, pp 2122-2123.

[29] Arotcarena, M.; Heise, B.; Ishaya, S.; Laschewsky, A., "Switching the Inside and the Outside of Aggregates of WaterSoluble Block Copolymers with Double Thermoresponsivity", J. Am. Chem. Soc. 2002, vol 124, pp 3787-3793.

[30] Izumrudov, V. A.; Zelikin, A. N.; Zhiryakova, M. V.; Jaeger, W.; Bohrisch, J., "nterpolyelectrolyte Reactions in Solutions of Polycarboxybetaines”, J. Phys. Chem. B 2003, vol 107, pp 79827986.

[31] Johnson, K. M.; Fevola, M. J.; McCormick, C. L., "Hydrophobically modified acrylamide-based polybetaines. I. Synthesis, characterization, and stimuli-responsive solution behavior”, J. Appl. Polym. Sci. 2004, vol 92, pp 647-657.

[32] Miyazawa, K.; Winnik, F. M., "Synthesis of PhosphorylcholineBased Hydrophobically Modified Polybetaines", Macromolecules 2002, vol 35, pp 2440-2444.

[33] Bohrisch, J.; Schimmel, T.; Engelhardt, H.; Jaeger, W. Charge "Interaction of Synthetic Polycarboxybetaines in Bulk and Solution”, Macromolecules 2002, vol 35, pp 4143-4149.

[34] Lowe, A. B.; Billingham, N. C.; Armes, S. P., "Synthesis and Properties of Low-Polydispersity Poly(sulfopropylbetaine)s and Their Block Copolymers”, Macromolecules 1999, vol 32, pp 2141-2148.

[35] Waziri, S. M.; Abu-Sharkh, B. F.; Ali, S. A., "Protein partitioning in aqueous two-phase systems composed of a $\mathrm{pH}$-responsive copolymer and poly(ethylene glycol)”, Biotechnol. Prog. 2004, vol 20, pp 526-532.

[36] Lowe, A. B.; Vamvakaki, M.; Wassall, M. A.; Wong, L.; Billingham, N. C.; Armes, S. P.; Lloyd, A. W., "Well-defined sulfobetaine-based statistical copolymers as potential 
antibioadherent coatings”, J. Biomed. Mater. Res. 2000, vol 52, pp 88-94.

[37] Schulz, D. N.; Peiffer, D. G.; Agarwal, P. K.; Larabee, J.; kaladas, J. J.; Soni, L.; Handwerker, B.; Garner, R. T. , "Phase behaviour and solution properties of sulphobetaine polymers”, Polymer 1986, vol 27, pp 1734-1742.

[38] Zhou, S. Q; Burger, C.; Chu, B.; Sawamura, M.; Nagahama, N.; Toganoh, M.; Hackler, U.; Isobe, H.; Nakamura, E., "Spherical bilayer vesicles of fullerene-based surfactants in water: A laser light scattering study”, Science 2001, vol 291, pp 1944-1947.

[42] Dai, S.; Tam, K. C.; Jenkins, R. D., "Microstructure of Dilute Hydrophobically Modified Alkali Soluble Emulsion in Aqueous Salt Solution”, Macromolecules 2000, vol 33,pp 404-411. 